\title{
PURIFICAÇÃO DA ENZIMA POLIFENOLOXIDASE (PFO) DE POLPA DE PINHA (Annona squamosa L.) MADURA ${ }^{1}$
}

\author{
Eliza Dorotea Pozzobon de A. LIMA ${ }^{2, *}$, \\ Gláucia Maria PASTORE ${ }^{3}$ Carlos Alberto de A. LIMA²
}

\begin{abstract}
RESUMO
A PFO (EC 1.10.3.2) extraída de polpa de pinha madura (Annona squamosa L.), foi parcialmente purificada por fracionamento em sulfato de amônio a 80\% e purificada 411 (Fração I) e 118 (Fração II) vezes após cromatografia em coluna de troca iônica em DEAE-Toyopearl 650M, e 566 vezes em coluna de Toyopearl HW55F. A enzima da fração mais ativa foi caracterizada bioquimicamente. Quanto aos parâmetros cinéticos, a enzima apresentou valores $\mathrm{de}_{\mathrm{m}}$ e $\mathrm{V}_{\text {max }}$ de $7,14 \mathrm{mM}$ e 302,0 unidades $/ \mathrm{min} / \mathrm{ml}$ para catecol e $25,0 \mathrm{mM}$ e 180,2 unidades/min/ml para L-dopa respectivamente, substratos que demonstraram maior especificidade. O peso molecular foi estimado em 90.700 daltons através de filtração em gel Sephadex G-200. O teor de cobre da enzima purificada encontrado foi de $11 \mathrm{ppm} /$ peso da amostra liofilizada. Quanto à composição de aminoácidos, a PFO apresentou maiores teores de ácido aspártico, ácido glutâmico e lisina e menores teores de metionina, arginina e tirosina, com ausência de cisteína.
\end{abstract}

Palavras-chave: purificação; polifenoloxidase; pinha; Annona squamosa L.

\section{SUMMARY}

PURIFICATION OF POLYPHENOLOXIDASE (PPO) FROM RIPE CUSTARD APPLE (Annona squamosa L.) PULP. The PPO (EC 1.10.3.2) extract of ripe custard apple (Annona squamosa L.) pulps, was partially purified by ammonium sulphate fractionation and purified 411 (Fraction I) and 118 (Fraction II) fold in an ion exchange column of DEAE-Toyopearl $650 \mathrm{M}$, and 566 fold in a gel column of Toyopearl HW 55F. The enzyme of the most active fraction was characterized biochemically. The partially purified and purified enzyme used the o-diphenols as substrates and no activity towards monophenols was detected. With respect to the kinetic parameters, the purified enzyme presented values for $\mathrm{K}_{\mathrm{m}}$ and $\mathrm{V}_{\max }$ of $7.14 \mathrm{mM}$ and 302.0 units $/ \mathrm{min} / \mathrm{ml}$ for catechol and $25.0 \mathrm{mM}$ and $180.2 \mathrm{units} / \mathrm{min} / \mathrm{ml}$ for L-dopa respectively, substrates which show greater specificity. The molecular weight was estimated as 90.700 daltons using gel filtration on Sephadex G-200. In the analysis of copper, the purified enzyme gave a value of $11 \mathrm{ppm}$ by weight of the liofilized sample. The amino acid composition of the custard apple fruit PPO, presented greater amounts of aspartic acid, glutamic acid and lysine and smaller amounts of methionine, arginine and tyrosine, with an absence of cysteine.

Keywords: purification; polyphenoloxidase; custard apple; Annona squamosa L.

${ }^{1}$ Recebido para publicação em 08/11/00. Aceito para publicação em 26/03/01.

${ }^{1}$ Parte do trabalho de Tese de Doutorado em Ciências de Alimentos-UNICAMP

${ }^{2}$ Laboratório de Tecnologia de Alimentos-DSER-CCA-UFPb. Email:epozzob@zaz.com.br

${ }^{3}$ Laboratório de Bioquímica- Depto ${ }^{\circ}$ de Ciências de Alimentos FEA - UNICAMP - Caixa Postal 6121, CEP 13081-970, Barão Geraldo, Campinas, SP, Brasil.

${ }^{*}$ A quem a correspondência deve ser enviada.

\section{1 - INTRODUÇÃO}

As enzimas polifenoloxidases (PFO) são amplamente distribuídas na natureza, sendo primeiramente relacionadas com o escurecimento enzimático dos vegetais in natura, ocasionando perda da cor dos produtos de frutas e hortaliças processados e ou congelados, diminuição do valor nutricional, modificando as propriedades organoléticas, resultando na maioria dos casos em produtos com aparência ruim, os quais são rejeitados pelos consumidores [4]. Por outro lado, a PFO tem papel importante no desenvolvimento do sabor e cor dos alimentos como por exemplo do chá preto, diminuição do amargor e adstringência dos produtos do cacau e formação de aldeídos de aminoácidos [26, 29, 38].

A pinha (Annona squamosa L.), é originária da América Tropical sendo seu fruto um sincarpo arredondado, ovóide, esférico ou cordiforme, com 5 a $10 \mathrm{~cm}$ de diâmetro, formado por carpelos muito proeminentes na maioria dos cultivares, coberto externamente de saliências achatadas em forma de tubérculos e regularmente dispostos $[3,10,17]$. É também denominada de ata e fruta-do-conde [3] e em inglês conhecida como "custard apple" e "sugar apple", apresenta polpa branca ou amarela, com aroma agradável, muito doce, o que a torna importante para o consumo da fruta fresca e para a industrialização, sendo apropriada para elaboração de bebidas fermentadas e muito aceita na fabricação de sorvetes. Os plantios mais organizados de pinha estão localizados atualmente, no oeste do Estado de São Paulo, interior da Bahia, Pernambuco e Alagoas. De acordo com KAVATI [17], a situação atual de produção desta fruta no Brasil a coloca como a principal da família. Apesar da crescente demanda pela pinha, tanto para consumo in natura quanto para a indústria, existe escassez de conhecimentos sobre sua composição química, caracterização bioquímica e fisiologia de pós-colheita. LIAO et al [21] apresentaramna como um fruto climatérico, cuja maturação em condições ambientais $\left(20-25^{\circ} \mathrm{C}\right)$ e $80 \%$ de umidade relativa se processa de forma muito rápida, de 3-5 dias após a colheita, ocorrendo mudanças de textura e aroma, com conseqüente perda de aspecto e qualidade. $\mathrm{O}$ critério utilizado para colheita do fruto da pinha é o afastamento dos carpelos e coloração verde-amarelada dos tecidos intercarpelares.

Há um grande mercado potencial para exportação da pinha in natura, porém um dos obstáculos a ser vencido é a facilidade de escurecimento enzimático que a fruta apresenta, sendo este catalisado pela enzima polifenoloxidase (PFO), que por sua habilidade em uti- 
lizar o oxigênio molecular durante a oxidação de substratos fenólicos produz cor escura [27].

Algumas pesquisas têm sido realizadas para purificação da PPO de diferentes fontes vegetais, utilizando colunas cromatográficas de DEAE - Toyopearl 650M e colunas de Toyopearl HW 55F em diversas etapas da purificação com berinjela [7], com alface [8], maçãs [30]. Os estudos existentes na literatura relacionados com 0 grau de purificação da enzima PFO utilizando cromatografia de troca-iônica e filtração em gel com resinas empregadas neste trabalho, mostram resultados diferenciados dependendo da origem da planta e a forma como é extraída a PFO, podendo influenciar nos resultados finais. ANOSIKE \& AYAEBENE [2] estudando a PFO de inhame estimou o peso molecular da enzima em 115kDa em coluna de gel Sephadex G-100. GOODENOUGH et al [9], JANOVITZ-KLAPP et al [12] e WANG et al [32], apresentaram resultados de pesos moleculares de PPO de maçã obtidos por filtração em gel, detectando um único pico de atividade com peso molecular de $26 \mathrm{kDa}$ ou $46 \mathrm{kDa}$. Muitos resultados inicialmente parecem ser controvertidos, necessitando maiores estudos das propriedades moleculares das enzimas, para permitir o conhecimento do mecanismo fundamental de suas mudanças. O objetivo deste trabalho foi estudar a purificação da polifenoloxidase da polpa de pinha madura através de cromatografia de troca iônica e exclusão molecular.

\section{2 - MATERIAIS E MÉTODOS}

\section{1 - Material}

Pinhas cultivadas na região de Lins-SP, foram adquiridas na CEASA - Campinas - SP, colhidas com 80 a 100 dias de desenvolvimento após a floração, sendo analisadas no estádio de maturação comercial "maduro". A polpa obtida pela separação da casca e sementes, foi congelada em gelo seco e mantida à temperatura de $\left(-18^{\circ} \mathrm{C}\right)$ para posterior análise.

\section{2 - Extração}

O extrato enzimático da polpa de pinha madura foi obtido, utilizando-se $1000 \mathrm{~g}$ de amostra em $2000 \mathrm{~mL}$ de solução tampão fosfato de potássio $0,025 \mathrm{M}(\mathrm{pH} 7,5)$. A extração foi feita a $4^{\circ} \mathrm{C}$ em liquidificador, durante 3 minutos. O homogeneizado foi centrifugado a $11.000 \mathrm{xg}$ durante 15 minutos a $0^{\circ} \mathrm{C}$, e o sobrenadante mantido a $4^{\circ} \mathrm{C}$. Estas condições foram desenvolvidas de acordo LIMA \& PASTORE, [22] e LIMA [23]. Foram realizadas análises de atividade da enzima e teor de proteínas.

\section{3 - Determinação da atividade enzimática}

A atividade da PFO foi determinada através da mistura de reação constituída de $0,1 \mathrm{~mL}$ da solução de enzima purificada, $1,2 \mathrm{~mL}$ de substrato catecol $15 \mathrm{mM}$ em tampão fosfato de potássio 0,025M (pH 7,0) e $1,7 \mathrm{~mL}$ do mesmo tampão fosfato de potássio $0,025 \mathrm{M}(\mathrm{pH} 7,0)$, perfazendo um total de 3,0ml. Para o branco foi usado a mistura de solução tampão mais solução do substrato. A atividade da enzima foi calculada pela inclinação linear da curva. Uma unidade de atividade de PPO foi definida como a quantidade da enzima que ocasiona um aumento na absorbância de $0,001 / \mathrm{min} / \mathrm{mL}$ [31].

\section{4 - Fracionamento com sulfato de amônio}

Ao sobrenadante do extrato enzimático bruto (descrito anteriormente), foi adicionado sulfato de amônio em quantidade suficiente para fornecer $80 \%$ de saturação. O sal foi adicionado lentamente com agitação branda e a mistura permaneceu por 24 horas a $4^{\circ} \mathrm{C}$ para precipitação da enzima. A mistura foi centrifugada a 11.000xg por 15 minutos a $0^{\circ} \mathrm{C}$, reservando-se o precipitado. $\mathrm{O}$ precipitado foi dialisado contra água destilada em membrana de acetato por 24 ou 48 horas a $4^{\circ} \mathrm{C}$.

Após a diálise, a fração protéica foi precipitada com álcool etílico a 70\%, e sua separação realizada por centrifugação a $11.000 \times \mathrm{xg}$ durante 15 minutos a $0^{\circ} \mathrm{C}$, seca e pulverizada. $O$ material em pó foi denominado de enzima bruta.

\section{5 - Purificação da PFO de polpa de pinha madura}

Após o fracionamento da PFO com sulfato de amônio, foi realizado uma purificação posterior através de cromatografia em coluna de DEAE-Toyopearl $650 \mathrm{M}$ e Toyopearl HW-55F. Na montagem da coluna foram aplicados $35 \mathrm{~mL}$ da resina de DEAE- Toyopearl $650 \mathrm{M}$ previamente tratada com tampão fostato de potássio $0,05 \mathrm{M}(\mathrm{pH} 7,0)$, em coluna de vidro (Pharmacia) com $1,5 \mathrm{~cm}$ de diâmetro $\times 30 \mathrm{~cm}$ de comprimento, sendo o equilíbrio da coluna efetuado pela adição de 5 a 10 vezes o volume da coluna de solução tampão fosfato

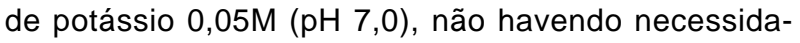
de do tratamento com solução ácida ou alcalina [16]. Após o equilíbrio da coluna, aplicou-se uma quantidade de $5 \mathrm{~mL}$ da amostra referente ao sobrenadante da enzima parcialmente purificada em pó, contendo $0,4 \mathrm{~g}$ de amostra dissolvidos em $10 \mathrm{~mL}$ de tampão fosfato de potássio $0,025 \mathrm{M}(\mathrm{pH} \mathrm{7,0)}$, permanecendo em extração durante uma hora, seguido de centrifugação a $11.000 x g$ durante 15 minutos a $0^{\circ} \mathrm{C}$. A amostra foi aplicada em coluna de $1,5 \mathrm{~cm} \times 30 \mathrm{~cm}$, mantida a $\pm 15^{\circ} \mathrm{C}$. Foram coletadas frações de $2 \mathrm{~mL}$ na vazão de $20 \mathrm{~mL} /$ hora. A amostra foi eluída inicialmente com o mesmo tampão de equilíbrio e posteriormente aplicou-se solução tampão fosfato de potássio $0,05 \mathrm{M}(\mathrm{pH} \mathrm{7,0)} \mathrm{com}$ solução gradiente de $\mathrm{NaCl}$ de $0,1 \mathrm{M}, 0,2 \mathrm{M}, 0,3 \mathrm{M}$ e $0,5 \mathrm{M}$, utilizando-se coletor de frações com registrador automático. O perfil de eluição das proteínas foi acompanhado pela medida da absorbância a $280 \mathrm{~nm}$ em espectrofotômetro, e a atividade da enzima PFO determinada nas frações que apresentaram picos de absorbância nesse comprimento de onda. As frações que apresentaram maior atividade enzimática foram reunidas e dialisadas contra água destilada por 24 horas a $4^{\circ} \mathrm{C}$, em seguida, determinou-se o teor de proteína pelo método de LOWRY et al [25] e a atividade da PFO, para posterior aplicação em coluna de Toyopearl HW-55F. 
A preparação do gel de polímero hidrofílico poroso de pérolas de polivinil, Toyopearl HW-55 seguiu o manual de empacotamento da TOYOPEARL e dados de pesquisa de KATO et al [13, 14, 15]. A resina foi ressuspensa com agitação vigorosa e a quantidade de suspensão desejada foi transferida para um béquer. Foram adicionados 4 vezes o volume de água destilada, misturando-se bem e deixando-se acomodar até formar uma camada estável e firme, repetindo este passo por três vezes. O tempo de acomodação depende do tamanho da partícula do gel (grau), sendo utilizado o grau fino (F), com tempo de acomodação de 30-45 minutos. Descartou-se o sobrenadante contendo as partículas finas. Quando caracterizado o final da suspensão, adicionou-se o tampão fosfato de potássio 0,025 (pH 7,0) para equilibrar a coluna. Utilizou-se coluna de vidro da Pharmacia $(1,5 \times 80 \mathrm{~cm})$ empacotando-se o gel de maneira rápida e contínua por gravidade. A amostra de $10 \mathrm{~mL}$, proveniente da purificação em coluna DEAEToyopearl 650M foi eluída com tampão fosfato de potássio $0,025 \mathrm{M}(\mathrm{pH} \mathrm{7,0)}$. As frações de $5 \mathrm{~mL}$ foram coletadas a cada 15 minutos em coletor de frações com registrador automático. A eluição das proteínas foi monitorada a 280nm, e a atividade determinada nas frações que apresentaram picos de absorbância nesse comprimento de onda. Os eluatos obtidos nas colunas cromatográficas foram congelados e uma parte liofilizados para estudos posteriores.

\section{6 - Eletroforese}

Para identificar e monitorar proteínas durante as etapas de purificação, além de verificar a homogeneidade das frações utilizou-se eletroforese em gel de poliacrilamida-dodecil sulfato de sódio (SDS-PAGE) conforme método descrito por WEBER \& OSBORN [33] e LAEMMLI [20] com eventuais modificações.

As amostras provenientes das colunas cromatográficas foram concentradas por liofilização e posteriormente preparadas para eletroforese por mistura com tampão Tris- $\mathrm{HCl}(\mathrm{pH} 8,8)$, solução de glicerina $20 \%$ e azul de bromofenol 0,001\%. Foram aplicados $20 \mu \mathrm{l}$ de amostras em condições não desnaturante. O experimento foi conduzido usando-se tampão Tris/glicina $(\mathrm{pH}$ $8,3)$, gel de concentração $3,0 \%$ e gel de separação a $10 \%$ de poliacrilamida, em cuba vertical (sistema Mini Protean II-BIORAD), empregando-se corrente de 100V, $21 \mathrm{~mA}, 2 \mathrm{~W} /$ placa de gel por cerca 2 horas a $4^{\circ} \mathrm{C}$. Após o término da corrida, para a coloração das proteínas utilizou-se o corante Coomassie brilliant blue G-250, e para verificar a atividade da enzima foi efetuado a imersão de outro gel em solução de catecol $10 \mathrm{mM}$ foi adicionado $0,05 \%$ de o-fenilendiamina e após o aparecimento da banda, lavou-se o gel com solução de ácido ascórbico $1 \mathrm{mM}$, durante 5 minutos. O gel corado foi colocado em água destilada e posteriormente em etanol 30\%, segundo WESCHE-EBELING \& MONTGOMERY [34].

\section{7 - Determinação do peso molecular da PFO}

A enzima purificada teve seu peso molecular estimado por filtração em gel Sephadex G-200, ( coluna de
$100 \mathrm{~cm} \times 2,5 \mathrm{~cm}$ ) de acordo com WHITAKER [36] e ANDREWS [1], utilizando-se como padrões as seguintes proteínas (SIGMA MW-GF 200): álcool desidrogenase (150.000 daltons), soro albumina bovina (66.000 daltons), anidrase carbônica (29.000 daltons) e citocromo C (12.400 daltons). A coluna foi previamente equilibrada com tampão fosfato de potássio $0,025 \mathrm{M}(\mathrm{pH} \mathrm{7,0)}$. Todos os padrões de peso molecular foram dissolvidos em $2 \mathrm{~mL}$ do tampão fosfato de potássio $0,025 \mathrm{M}(\mathrm{pH} \mathrm{7,0)}$, contendo $5 \%$ de glicerol. Utilizou-se como frente de eluição $10 \mathrm{mg}$ de Blue Dextran 2.000 diluído em tampão fosfato de potássio $0,025 \mathrm{M}(\mathrm{pH} \mathrm{7,0)}$, com $5 \%$ de glicerol. Uma amostra de $10 \mathrm{ml}$ de solução de PPO purificada, contendo ao redor de 1,0mg de proteína, foi eluída na mesma coluna, com uma vazão de $10 \mathrm{ml} /$ hora, coletando-se frações do eluente de $2 \mathrm{ml}$, sendo monitoradas a $280 \mathrm{~nm}$.

\section{8 - Determinação dos parâmetros cinéticos de $K_{m} e$ $\mathrm{V}_{\max }$}

O efeito da concentração dos substratos catecol e L-dopa ( $4 \mathrm{mM}$ a $25 \mathrm{mM}$ ) na atividade da PFO purificada, foi investigado a $20^{\circ} \mathrm{C}, \mathrm{pH} 7,0$. Os valores de $\mathrm{K}_{\mathrm{m}}$ e $\mathrm{V}_{\max }$ foram determinados utilizando-se o gráfico de LINEWEVER-BURK [24].

\section{9 - Determinação de cobre}

O teor de cobre presente na PFO foi determinado em amostras de enzima purificada. A técnica analítica utilizada foi absorção atômica por atomização em chama, tendo como procedimento a abertura da amostra por digestão ácida, seguida da quantificação do metal por absorção por atomização com chama, usando parâmetros do equipamento conforme manual de instrução do fornecedor do equipamento "VARIAN AAG".

\subsection{0 - Composição de aminoácidos}

A composição de aminoácidos da enzima purificada, foi analisada após hidrólise ácida com $\mathrm{HCl} 6 \mathrm{~N}$ à vácuo na temperatura de $110^{\circ} \mathrm{C}$ durante 22 horas. A amostra foi recuperada no diluente $\mathrm{pH} \mathrm{2,2} \mathrm{(Pickering).} \mathrm{A} \mathrm{sepa-}$ ração dos aminoácidos foi realizada em coluna de troca-iônica e reação pós-coluna com ninidrina. Os aminoácidos foram quantificados em analisador DIONEX DX-300, utilizando-se mistura padrão de aminoácidos (PIERCE) como referência.

\section{3 - RESULTADOS E DISCUSSÃO}

\section{1 - Purificação da enzima PFO}

O perfil cromatográfico da coluna de DEAE-Toyopearl 650M apresentado na Figura 1, mostra que a atividade de PFO foi obtida em dois picos. A PFO adsorvida na resina eluída em tampão fosfato de potássio $0,025 \mathrm{M}$ $\mathrm{pH} 7,0$ contendo $0,1 \mathrm{M}$ de $\mathrm{NaCl}$, foi denominada de Fração-I, demonstrando elevada atividade; a fração eluída

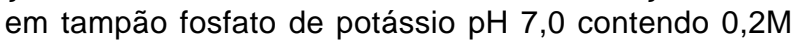
de $\mathrm{NaCl}$, de Fração-II, apresentou baixa atividade da enzima. As frações ativas do primeiro pico de atividade 
da enzima PFO foram reunidas, dialisadas contra água destilada a $4^{\circ} \mathrm{C}$ e aplicadas em coluna de Toyopearl HW 55F. As frações do segundo pico de atividade foram reunidas e dialisadas, porém não foram aplicadas em coluna de Toyopearl HW 55F devido o baixo teor de proteínas, sendo comprovado por resultados posteriores de eletroforese, pelo não aparecimento de bandas.

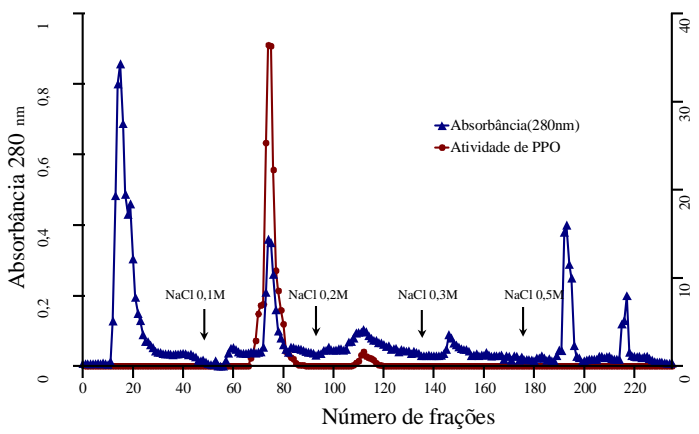

FIGURA 1. Cromatografia da PFO de polpa de pinha madura em coluna de DEAEToyopearl 650M.

As frações ativas reunidas obtidas na Fração-I em coluna de DEAE-Toyopearl 650M foram aplicadas na coluna de Toyopearl HW 55F, apresentando o perfil cromatográfico mostrado na Figura 2. A atividade da enzima foi obtida em um único pico, e as frações coletadas após separações em várias colunas foram reunidas e denominadas de enzima purificada.

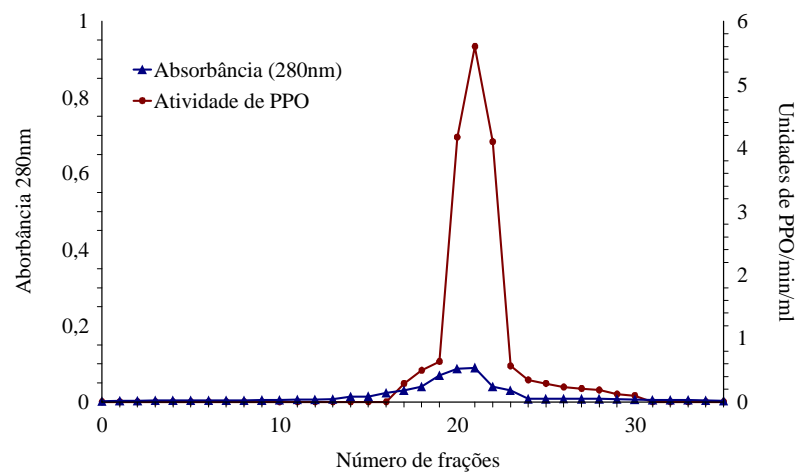

FIGURA 2. Cromatografia da Fração-I da PFO de polpa de pinha madura em coluna de Toyopearl HW 55F.

Verificou-se a homogeneidade das frações quando utilizou-se eletroforese em gel de SDS-PAGE pelo aparecimento de uma única banda na última etapa de purificação em coluna de Toyopearl HW 55F (Figura 3), quando corou-se o gel com Coomassie brilliant blue G-250, a qual coincidiu com a banda de atividade.

FUJITA et al [8], purificaram a PFO de alface em coluna semelhante, e obtiveram o mesmo comportamento típico da coluna final de gel Toyopearl HW 55F com um único pico de atividade. Posteriormente, FUJITA et al [6] em estudos de purificação da PFO de repolho, utilizando na etapa final colunas cromatográficas de Toyopearl HW 55F, também obtiveram perfil cromatográfico idêntico com um único pico.

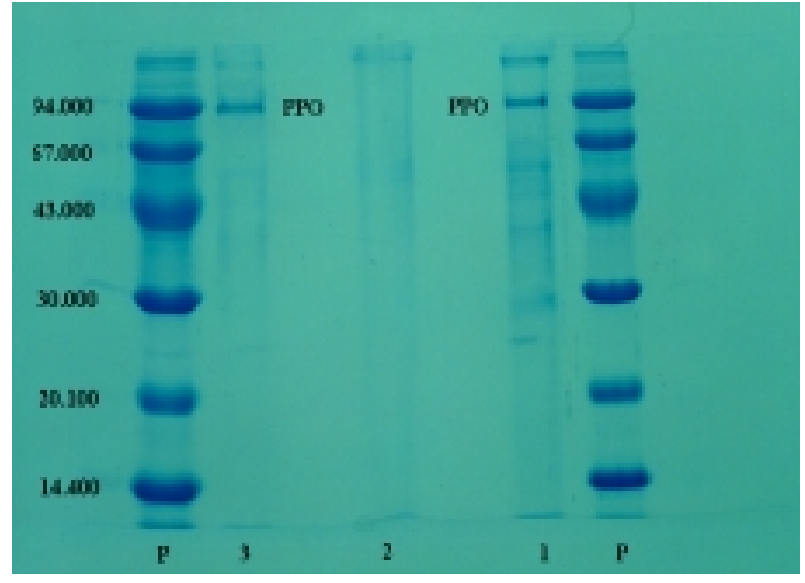

FIGURA 3. Eletroforese de PPO purificada em gel SDS-PAGE. $\mathrm{P}=$ padrões de proteína: fosforilase b $(94.000 \mathrm{Da})$, soro albumina bovina $(67.000 \mathrm{Da})$, ovoalbumina $(43.000 \mathrm{Da})$, anidrase carbônica (30.000 Da), inibidor de tripsina (20.100 Da) e a lactoalbumina (14.400 Da). 1- PPO (Fração I) DEAE Toyopearl 650M; 2- PPO (Fração II) DEAE-Toyopearl 650M; 3- PPO Toyopearl HW 55F.

A Tabela 1 apresenta o sumário dos processos utilizados na purificação da PFO de polpa de pinha madura.

TABELA 1. Purificação da enzima PFO

\begin{tabular}{lcccccc}
\hline \multicolumn{1}{c}{ Etapas } & $\begin{array}{c}\text { Volume } \\
(\mathrm{mL})\end{array}$ & $\begin{array}{c}\text { Atividade } \\
\text { total } \\
(\mathrm{U} / \mathrm{min} / \mathrm{mL}) \\
\left(\mathrm{x} 10^{3}\right)\end{array}$ & $\begin{array}{c}\text { Proténa } \\
\text { total } \\
(\mathrm{mg} / \mathrm{mL})\end{array}$ & $\begin{array}{c}\text { Atividade } \\
\text { específica } \\
(\mathrm{U} / \mathrm{mg} \mathrm{prot}) \\
\left(\mathrm{x} 10^{3}\right)\end{array}$ & $\begin{array}{c}\text { Fator de } \\
\text { purificação }\end{array}$ & $\begin{array}{c}\text { Recu- } \\
\text { peração } \\
(\%)\end{array}$ \\
\hline Extrato bruto & 850 & 16481,5 & 2133,5 & 7,73 & 1 & 100 \\
\hline $\begin{array}{l}\text { Precipitado com } \\
\left(\mathrm{NH}_{4}\right)_{2} \mathrm{SO}_{4} \mathrm{e}\end{array}$ & 200 & 10256,0 & 420,0 & 24,4 & 3,2 & 62,2 \\
\hline dialisado & & & & & & \\
\hline $\begin{array}{l}\text { Cromatografia em } \\
\text { coluna DEAE- }\end{array}$ & & & & & & \\
$\begin{array}{l}\text { Toyopearl 650M } \\
\text { (Fração I) }\end{array}$ & 40 & 634,8 & 0,2 & 3174,0 & 411 & 3,85 \\
(Fração II) & 19 & 27,3 & 0,03 & 910,0 & 118 & 0,17 \\
\hline $\begin{array}{l}\text { Cromatografia em } \\
\text { coluna Toyopearl } \\
\text { HW55F }\end{array}$ & 10 & 52,5 & 0,012 & 4375,0 & 566 & 0,32 \\
\hline
\end{tabular}

A PFO na Fração-I foi purificada 411 vezes após cromatografia de DEAE - Toyopearl 650M, com 3,85\% de recuperação e atividade específica de 3174,0 unidades/mg de proteína $\left(\times 10^{3}\right)$. A cromatografia em coluna Toyopearl HW 55F, correspondente à última etapa de purificação deste experimento, resultou num aumento de 566 vezes na atividade específica da PPO, equivalente a 4375,0 unidades/mg $\left(\times 10^{3}\right)$ de proteína. Estes resultados demonstraram alto grau de purificação da enzima PPO, quando submetida à cromatografia em colunas de DEAE-Toyopearl 650M e Toyopearl HW 55F.

\section{2 - Determinação do peso molecular da PFO por filtração em gel em coluna de Sephadex G-200}

A Figura 4 ilustra a relação entre o volume de eluição e o peso molecular das proteínas padrões e da enzima PFO purificada em coluna de Sephadex G-200, sendo 
observado um único pico de atividade, verificando-se a homogeneidade das frações quando utilizou-se SDSPAGE, pelo aparecimento de uma única banda na última etapa de purificação em coluna de Toyopearl HW $55 \mathrm{~F}$, quando corou-se o gel em Coomassie brilliant blue G-250, demonstrado por LIMA [22].

O peso molecular da PFO purificada de polpa de pinha madura foi estimado em 90.700 daltons através da filtração em gel de Sephadex G-200.

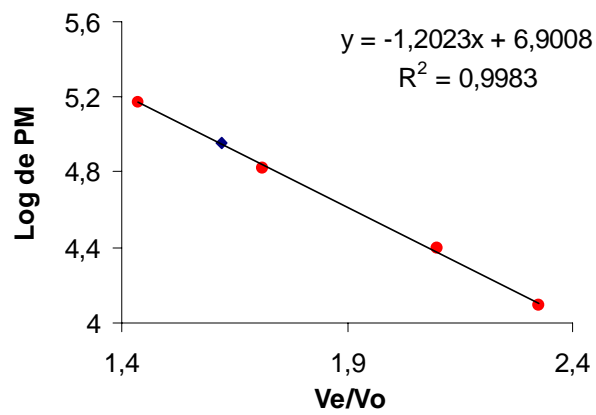

FIGURA 4. Peso molecular da PFO purificada em coluna de Sephadex-G200.

O peso molecular estimado para a enzima PFO de pinhas em filtração em gel, foi maior do que o encontrado em outra fonte da enzima, como repolho [6], estimado ao redor de 29.000 a 40.000 daltons. KINDRON et al [18] relataram que o peso molecular da PFO de uva foi de 80.000 daltons, ANOSIKE \& AYAEBENE [2] em pesquisa com inhame, encontraram peso molecular de 115.000 para a PFO com coluna de Sephadex G-100. Os mesmos autores relatam que os pesos moleculares variam dependendo da fonte do vegetal, método de extração e procedimentos de determinação.

\section{3 - Determinação dos parâmetros cinéticos de $\mathrm{K}_{\mathrm{m}} \mathrm{e}$ $\mathbf{V}_{\text {max }}$ de PFO de pinha}

A enzima apresentou maior afinidade para o substrato catecol com $\mathrm{K}_{\mathrm{m}}$ de $7,14 \mathrm{mM}$ e $\mathrm{V}_{\max }$ de $302,0 \mathrm{U} / \mathrm{min} / \mathrm{mL}$ (Figura 5). Com L-dopa os valores foram de $25,0 \mathrm{mM}$ para $\circ \mathrm{K}_{\mathrm{m}}$ e de $180,2 \mathrm{U} / \mathrm{min} / \mathrm{mL}$ para $\mathrm{V}_{\max }$ (Figura 6). A afinidade da PPO pelo substrato, é dependente da origem da enzima (tipo de planta), como foi observado por VAMOS-VIGYÁZÓ [37], WESCHE-EBELING \& MONTGOMERY [34, 35] e OKTAY et al. [31].

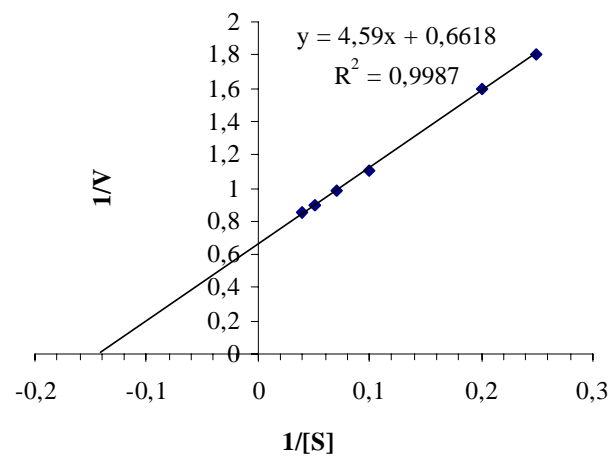

FIGURA 5. $\mathrm{K}_{\mathrm{m}}$ e $\mathrm{V}_{\max }$ de PFO de polpa de pinha madura com o substrato catecol.

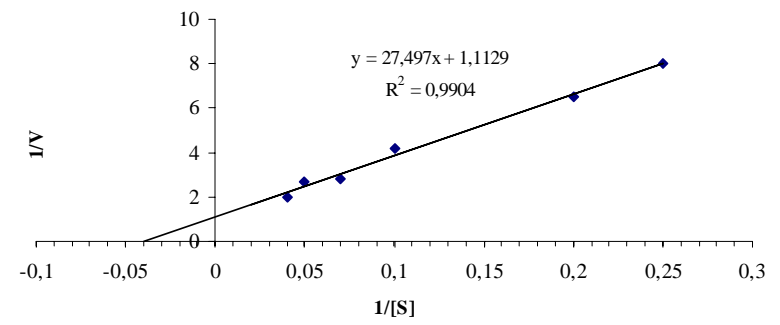

FIGURA 6. $\mathrm{K}_{\mathrm{m}}$ e $\mathrm{V}_{\text {max }}$ de PFO de polpa de pinha madura com Ldopa como substrato.

\section{4 - Teor de cobre}

A análise de cobre da enzima PFO purificada determinada por absorção atômica de acordo com a metodologia descrita, apresentou valores de cobre de $11 \mathrm{ppm} /$ peso de amostra liofilizada, caracterizando-se como uma metaloenzima, cujo valor se assemelha àquele obtido por FLICK et al [5], que comparou a quantidade de cobre presente na enzima PFO de diferentes variedades de berinjela com a respectiva atividade.

KINDRON et al [19] apresentaram o conteúdo de cobre de $0,04 \%$, como sendo uma quantidade muito pequena, sugerindo que o cobre pode ter sido perdido durante a purificação. Relataram ainda, que o conteúdo mínimo de cobre da enzima é de um átomo por molécula. As polifenoloxidases são metaloenzimas contendo ao redor de $0,2 \%$ de cobre, no entanto, sua distribuição dentro da molécula não é bem definida, determinando que o conteúdo de cobre seja em torno de um átomo por cadeia de polipeptideos ou subunidades da molécula.

MAYER \& HAREL [28] ressaltaram que os dados do conteúdo de cobre devem ser analisados com certo cuidado, devido à remoção parcial do cobre que ocorre dependendo do tipo de extração, variando de acordo com o grau de purificação e ou ação catalítica. De acordo com VAMOS-VIGYÁZÓ [37], assume-se que um monômero tenha massa molecular ao redor de 30.000 daltons e contém um átomo de cobre.

\section{5 - Composição de aminoácidos da PPO purificada de polpa de pinha madura}

A Tabela 2 apresenta o resultado da análise dos aminoácidos detectados na PPO de polpa de pinha madura. A concentração de cada aminoácido foi muito baixa, provavelmente devido aos baixos teores de proteínas da amostra analisada o que dificulta a sua quantificação e a reprodutibilidade dos resultados. Os aminoácidos presentes em maior concentração foram ácido aspártico, ácido glutâmico e lisina, com menores teores de metionina, arginina e tirosina, e ausência de cisteina. O triptofano não foi determinado, uma vez que ele é totalmente destruído durante a hidrólise ácida.

Estes resultados se assemelham àqueles apresentados por KINDRON et al [19] para a PFO de uva, que possui uma grande quantidade ácido aspártico, seguido do ácido glutâmico, além de conter pouca cisteína, histidina e metionina. 
TABELA 2. Composição de aminoácidos da enzima PFO de polpa pinha madura.

\begin{tabular}{lcc}
\hline \multicolumn{1}{c}{ Aminoácido } & $\mu \mathrm{g} / \mathrm{mg}$ de amostra & $\%$ \\
\hline Ácido aspártico & 854.242 & 11,4 \\
Treonina & 360.250 & 4,8 \\
Serina & 501.899 & 6,7 \\
Ácido glutâmico & 1200.476 & 16,0 \\
Prolina & 310.527 & 4,1 \\
Glicina & 342.398 & 4,6 \\
Alanina & 506.479 & 6,8 \\
Cisteína & 0.000 & - \\
Valina & 430.981 & 5,7 \\
Metionina & 14.865 & 0,2 \\
Isoleucina & 298.227 & 4,0 \\
Leucina & 514.571 & 6,9 \\
Tirosina & 179.131 & 2,4 \\
Fenilalanina & 300.458 & 4,0 \\
Lisina & 931.181 & 12,4 \\
NH & 364.819 & 4,9 \\
Histidina & 260.858 & 3,5 \\
Triptofano & ND* & - \\
Arginina & 128.680 & 1,7 \\
\hline${ }^{*}$ ND = Não determinado. O triptofano é destruído durante a hidrólise ácida.
\end{tabular}

INTERESSE RUGGIERO [11], ZAWISTOWSKI et al. [40] citados por ZAWISTOWSKI et al [39] apresentaram a composição de aminoácidos para PFO de várias fontes, comparando a enzima do Neurospora, alcachofra, trigo, uva, espinafre, batata e cogumelo. $O$ ácido aspártico e o ácido glutâmico são os que aparecem em maior quantidade, enquanto a cisteína, metionina, arginina, histidina e triptofano aparecem em concentrações menores.

Segundo MURATA et al [30] a PFO purificada de maçãs apresentou a composição de aminoácidos e as proporções semelhantes as encontradas na PFO de pinhas, encontrando em maior quantidade ácido aspártico, ácido glutâmico e lisina e em menor os aminoácidos sulfurados. Na enzima PFO da maçã foram encontradas pequenas quantidades de aminoácidos sulfurados, resultados semelhantes aos encontrados em outras PfOs purificadas de Neurosporas, cogumelos, batatas e uvas.

\section{4 - CONCLUSÕES}

- O sistema de purificação da PFO por cromatografia em coluna de troca-iônica DEAEToyopearl 650M e em gel Toyopearl HW 55F foi muito eficiente, apresentando valores de purificação de 411 vezes após cromatografia em DEAE-Toyopearl 650M e 566 vezes em Toyopearl HW 55F.

- A enzima PFO de polpa de pinha madura apresentou especificidade distinta por catecol com $\mathrm{K}_{\mathrm{m}}$ de $7,14 \mathrm{mM} \mathrm{e} \mathrm{V}_{\max }$ de $302,0 \mathrm{U} / \mathrm{min} / \mathrm{mL}$ demonstrando atividade para substratos o-difenóis e nenhuma atividade para monofenóis, caracterizando-se, portanto como uma catecolase.

- A PFO purificada apresentou peso molecular estimado em 90.700 daltons por filtração em gel de Sephadex G-200.

- Os aminoácidos presentes em maior concentração foram ácido aspártico, ácido glutâmico e lisina, com menores teores de metionina, arginina e tirosina, e ausência de cisteína. O triptofano não foi determinado, uma vez que ele é totalmente destruído durante a hidrólise ácida.

Conclui-se, portanto, que a partir dos resultados deste estudo, que os processos de purificação, aos quais a enzima foi submetida, levaram à obtenção da enzima com um alto grau de pureza.

\section{5 - REFERÊNCIAS BIBLIOGRÁFICAS}

[1] ANDREWS, P. The gel-filtration behaviour of proteins related to their molecular weights over wide range. Biochemistry Journal, v.98, p. 595-605, 1965.

[2] ANOSIKE, E.O.; AYAEBENE, A.O. Purification and some properties of polyphenoloxidase from the yam tubers, Discorea bulbifera. Phytochemitry, v.20, n.12, p.26252628, 1981.

[3] COUCEIRO, E.M. Pinha, fruto do conde ou ata, sua cultura e origem. Publicação da CEASA, Recife, v.1, n.8, p.1973.

[4] COSENTEG, M.Y.; LEE, C.Y. Changes in apple polyphenoloxidase and polyphenol concentration in relation to degree of browning. Journal of Food Science, v. 52, n. 4, p. 985-989, 1987.

[5] FLICK, G.J.; ORY, R.L.; St.ANGELO, A.J. Comparison of nutrient composition and of enzyme activity in purple, green, and white eggplant. Journal Agricultural Food Chemistry, v.25, n.1, p.117-120, 1977.

[6] FUJITA, S.; SAARI, N.; MAEGAWA, M.; TETSUDA, T.; HAYASHI, N.; TONO, T. Purification and properties of polyphenol oxidase from cabbage (Brassica oleracea $\mathrm{L}$.). Journal Agricultural Food Chemistry, v. 43, p.1138-1142, 1995.

[7] FUJITA, S.; TONO, T. Purification and some properties of polyphenoloxidase in eggplant (Solanum melongena). Journal Science Food Agriculture, v. 46, p. 115-123, 1988.

[8] FUJITA, S.; TONO, T.; KAWAHARA, H. Purification of polyphenol oxidase in head lettuce (Lactuca sativa). Journal of Food Science, v.55, p. 643-651, 1991.

[9] GOODENOUGH, P.W.; KESSEL, S.; LEA, A.G.H.; LEFFLER, T. Mono and diphenolase activity from fruit of Malus pumila. Phytochemistry, v.22, p.359-363, 1983.

[10] GUSMAN, R.; ARAQUE, M.; GUIJARRO, G. Caracterizacion del anon (Annona squamosa) y su industrializacion a pequeña escala. Frutas Tropicales. Boletim informativo, n.6, p.23-26, 1985.

[11] INTERESSE, F. S.; RUGGIERO, P. Partial purification and some properties of wheat (Triticum aestivum) o-diphenolase. Journal Science Food Agricultural, v.31, p.459-466, 1980.

[12] JANOVITZ-KLAPP, A.; RICHARD, F.; NICOLAS, J. Polyphenol oxidase from apple. Partial purification and some properties. Phytochemistry, v.28, p.2903-2907, 1989.

[13] KATO, Y.; KOMIYA, K.; IWEDA, T.; SASAKI, H.; HASHIMOTO, T. Packing of Toyopearl column for gel filtration. I. Influence of packing velocity column performance. Journal of Chromatography, v.205, p.185-188, 1981.

[14] KATO, Y.; KOMIYA, K.; IWEDA, T.; SASAKI, H.; HASHIMOTO, T. Packing of Toyopearl column for gel filtration. II Dependence optical packing velocity on columm size. Journal of Chromatography, v.206, p.135-138, 1981.

[15] KATO, Y.; KOMIYA, K.; IWEDA, T.; SASAKI, H.; HASHIMOTO, T. Packing of Toyopearl column for gel filtration. III- Semiconstant-pressure packing. Journal of Chromatography, v.208, p.71-73, 1981. 
[16] KATO, Y.; NAKAMURA, K.; HASHIMOTO, T. Operational variables in medium-performance ion-exchange chromatography of proteins on DEAE-Toyopearl 650. Journal of Chromatography, v.256, p.143-150, 1983.

[17] KAVATI, R. Melhoramento em fruta-do-conde. In: SÃO JOSÉ, A.R.; SOUZA, I.V.B.; MORAIS, O.M.; REBOUÇAS, T.N.H. Anonáceas-Produção e mercado. Universidade Estadual do Sudoeste da Bahia: Vitória da Conquista, 1997. p.47-54.

[18] KINDRON, M.; HAREL, M.; MAYER, A.M. Catechol oxidase activity in grapes and wine. American Journal Enology Viticulture, v.29, n.1, p.30-35, 1978.

[19] KINDRON, M.; HAREL, E.; MAYER, A.M. Copper content and amino acid composition of catechol oxidase from clairette grapes. Phytochemistry, v.16, p.1050-1051, 1977.

[20] LAEMMLI, U.K. Cleavage of structural proteins during the assembly of the head of bacteriophage T4. Nature, v. 227, n. 15 , p. $680-685,1970$.

[21] LIAO, M.L.; LIU, M.S.; YANG, J.S. Respiration measurement of some important fruits in Taiwan. Acta Horticulturae, v. 138, p. 227-246, 1983.

[22] LIMA, E.D.P.A.; PASTORE, G.M. Purificação parcial e caracterização bioquímica da enzima polifenoloxidase (PPO) em fruto da família anonácea -pinha (Annona squamosa L.). Anais do II Simpósio Latino Americano de Ciência de Alimentos, Campinas: 1997. P.89, n.221.

[23] LIMA, E.D.P.A. Purificação e caracterização bioquímica da enzima polifenoloxidase (PPO) em fruto da família anonácea -pinha (Annona squamosa L.). Campinas, 1999. 132p. Tese (Doutorado em Ciência de Alimentos), Faculdade de Engenharia de Alimentos, Universidade Estadual de Campinas (Unicamp).

[24] LINEWEVER H.; BURK, D. The determination of enzyme dissociation constants. Journal of American Chemical Society, v. 56, p. 658-666, 1934.

[25] LOWRY, O. H.; ROSEBROUGH, N. J.; FARR, A. L.; RANDALL, R. J. Protein measurement with the Folin fenol reagent. Journal of Biological Chemistry, v.193, p. 265275, 1951.

[26] MAHANTA, P. K.; BORUAH, S. K. ; BORUAH, H. K.; KALITA, J.N. Changes of polyphenol oxidase and peroxidase activities and pigment composition of some manufactured black tea (Camellia sinensis L.). American Chemical Society, v. 41, p.272-276, 1993.
[27] MAYER, A.M. Polyphenol oxidases in plants-recent progress. Phytochemistry, v.26, n. 1, p.11-20, 1987.

[28] MAYER, A.M.; HAREL, E. Polyphenol oxidases in plants. Phytochemistry, v.18, p. 193-215, 1979.

[29] MOTODA, S. Formation of aldehydes from amino acids by polyphenol oxidase. Jounal of Fermentation Technology, v.57, n.5, p. 395-399, 1979.

[30] MURATA, M., KUROKAMI, C.; HOMMA, S. Purification and some properties of chlorogenic acid oxidase from apple (Malus pumila). Bioscience Biotechnology Biochemistry, v.56, n.11, p.1705 - 1710, 1992.

[31] OKTAY,M.; KÜFREVIOGLU, I.; KOCACALISKANI. SAKIROGLU, H. Polyphenoloxidase from Amasya apple. Journal of Food Science, v.60, n.3, p. 494-505, 1995.

[32] WANG, J. Y.; JIAO, H.J.; FAUST, M. Changes in the activities of catalase, peroxidase, and polyphenol oxidase in apple buds during bud break induced by thiadiazuron. Journal Plant Growth Regulation, v.10, p.33-39, 1991.

[33] WEBER, K.; OSBORN, M. The reability of molecular weight determination by dodecyl sulfate-polyacrylamide gel electrophoresis. The Journal of Biological Chemistry, v. 244, n. 16, p. 4406-4412, 1969.

[34] WESCHE-EBELING, P.; MONTGOMERY, M. W. Strawberry polyphenoloxidase: Purification and characterization. Journal of Food Science, v.55, n.5, p.1315-1319, 1990.

[35] WESCHE-EBELING, P.; MONTGOMERY, M. W. Strawberry polyphenoloxidase: extraction and partial characterization. Journal of Food Science, v. 55, n. 5, p. 1320-1351, 1990.

[36] WHITAKER, J.R. Determination of molecular weight of proteins by gel filtration on Sephadex. Analitical Chemistry, v.35, n.12, p.1950-1953, 1963.

[37] VÁMOS-VIGYÁZÓ, L. Polyphenoloxidase and peroxidase in fruit and vegetables. CRC - Critical Reviews in Food Science and Nutrition, n.49,1981.

[38] YOSHIYAMA, M.; ITO, Y. Decrease of adstringency of cacao beans by an enzymatic treatment. Nippon Shokuhin Kagaku Kogaku Kaishi, v.43, n.2, p. 124-129, 1996.

[39] ZAWISTWSKI, J. ; BILIADERIS, C.G.; ESKIN, N.A.M. Polyphenol Oxidase. In: ROBINSON, D. S.; ESKIN, N.A.M.. Oxidative Enzymes in Foods. London e New York: Elsevier Applied Science, 1991. cap.6, p.217-273

[40] ZAWISTWSKI, J. ; BILIADERIS, C.G.; MURRAY, E.D. Isolation and some properties of an acidic fraction of polyphenol oxidase from Jerusalem artichoke Helianthus tuberosus L.). Journal of Food Biochemistry, v.12, p.23-35, 1988. 